\title{
A Comparison of the Energy Policies in Developing Countries: a Case of Tanzania and China
}

\author{
Haji, Iddi Salum ${ }^{1}$, Wei Jianguo ${ }^{2}$ \\ ${ }^{1}$ School of Economics, Wuhan University of Technology, Wuhan $430070 \quad$ P. R. China \\ iddisalum2001@yahoo.com \\ ${ }^{2}$ School of Economics, Wuhan University of Technology, Wuhan 430070 P. R. China \\ weijg@whut.edu.cn
}

\begin{abstract}
This paper intended to compare energy policy issues in developing countries by comparing Tanzania and China. The comparison showed that there are differences in policy implementations between the two countries due to different levels of development and their pursuance of energy policies with different goals and strategies. China is more developed in the renewable energy sector and energy efficiency but has a higher $\mathrm{CO}_{2}$ emission while Tanzania has less $\mathrm{CO}_{2}$ emission, energy inefficiency and renewable energy at early stages.
\end{abstract}

Keywords: energy, energy policy,consumption, developing countries

\section{Introduction}

Energy is one among the major policy issue in the world for its contribution to the well being of the people and environment for sustainable economic growth. Policy makers are faced with difficult constraints of defining sustainable in terms of energy security, social equity and environmental impact mitigation. It was estimated that the energy demand will rise to 40 percent in the coming 20 years [1]. Reducing the greenhouse gas emissions for sustainable climate and meeting potential growing demand of global energy are among the major challenges in making a uniform global energy policy [2]

The world is currently faced with different levels of technological development, each level of development has different consumption patterns of energy .Developed countries pay attention in improving efficiency in energy production, transmission, distribution and consumption. Figure 1 below shows the world energy consumption by sector, industrial sector is leading in consuming 31 percent and residential is the least consumer using 22 percent. [3].

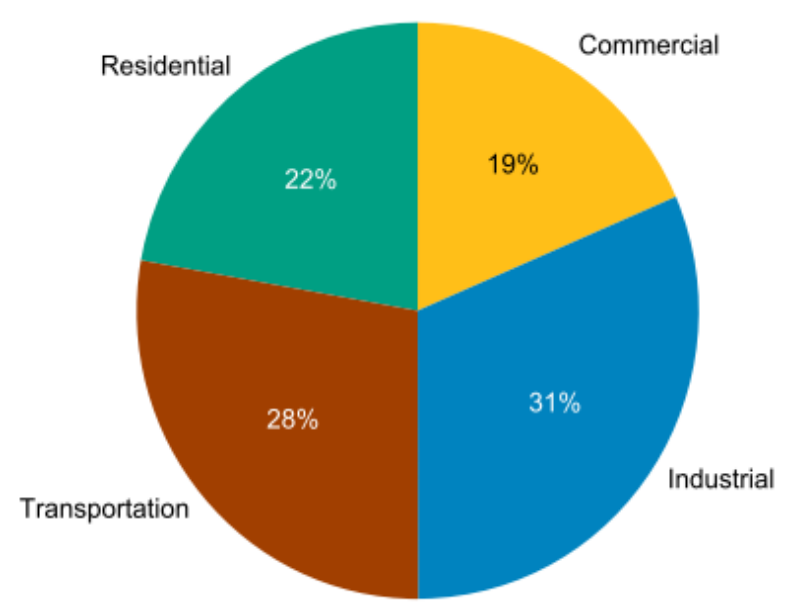

Figure 1: End-use sector share of total consumption, 2011. Source: U.S. Energy Information Administration / Annual Energy Review 2011

Developing countries are faced with rapid increase in population, improvement in living standards and economic growth which in turn influence the use of energy, in many countries this energy depends on imported oil [4].

Tanzania and China are among the developing countries facing many energy problems. The aim of this paper is to carry a comparative study between Tanzania and China in various issues relating to their energy policies .

The second and third sections of the paper covered the Tanzania's and China's energy aspects, the fourth section shows the comparisons in energy aspects between the two countries and last section is a conclusion . 


\section{Tanzanian Energy Policy}

Tanzania's first energy policy was established in 1992. The objectives the policy was to make a country to produce more hydroelectric power, to develop and utilize coal, natural gas, forest and agricultural residue for energy and last to reduce deforestation. The policy identified the short and medium term plans for achieving the long term goal of reducing the dependency on external energy sources and rational utilization of energy resources available in Tanzania. The energy policy was revised in 2003 due to the change of the government's roles from "Self Reliance" to the market liberalized economy. The revised policy targeted the market mechanism in achieving its energy objectives and efficient energy sector with a balance between government and other stakeholders [5].

Other energy policies formulated to assist energy sector are Forest Policy of 1998 that establish private woodlots and plantations for wood fuel production and give power to village governments to manage village forest reserves, Environmental Policy of 1997 that call for both environmental and biomass conservation and Land Policy of 1997 that give the president ownership of land, that direct sustainable use of land and recognizing customary and other use rights of land [6].

Tanzania depends on various sources of energy, these sources include bio-mass, fuel, coal and natural gases, hydroelectric energy. Solar, wind and geothermal energy resources are used in smaller amount. Tanzania is estimated to consume 22 million tones of oil equivalent a year (TOE) or 0.7 TOE per capita, while rural areas consume about 90 percent of the total National energy. Biomass-based fuel (e. g. Charcoal and firewood) provide more than 90 percent of primary energy, commercial energy supply from petroleum and electricity account for 8 percent and 1.2 percent respectively, while coal, solar and wind provide less than 1percent of the energy supply. The main source of energy is biomass and the important source of energy is imported petrol, 51 percent the petrol energy is used in Transport sector , 26 percent in industry sector , 10 percent household and the rest to another sector. The hydroelectric power serves 5 percent of the entire population by providing (1060Gwh) [5].

Figure 2 below shows that since 1980 to 2010
Tanzania has a higher consumption than production of primary energy, the energy requirement gap increases as the as the number of years are passing.

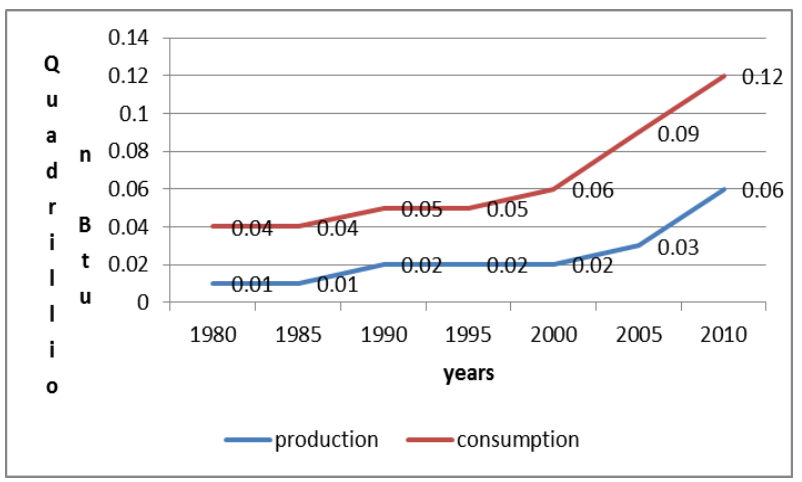

Fig 2:Total primary energy production and consumption a year in Tanzania

Source: Data from (www.indexmundi.com/energy)

The type of fuel used and physical feature of appliances used are among the factors that determine efficient use of energy and it was found that most of the developing countries lag behind in using energy efficient technology for example below 12 percent use traditional cooking stove [7]. Most Tanzanians use three stone stoves for fire woods and metal stoves that burn charcoal, these stoves lose more than 85 per cent of energy potential [6]. Despite the measure taken in rehabilitating and maintaining generation, transmission and distribution networks in improving quality of power, the technical and commercial losses have slowly been reduced from 24 percent in 2006, 23 percent in 2007 to 22 percent in 2008 the rate were below the international standard of 15 percent [8].

Transport sector in Tanzania is among the sector that contribute to the problem of air pollution by burning a high volume of petrol and diesel due to the increase in the number of vehicles and population. For example it is estimated that in Dar es Salaam there was an increase of 141 percent of carbon monoxide between 1987 and 1993 [9]. Tanzania is less developed with no intense industries that require a higher amount of energy. The emission of $\mathrm{CO} 2$ is very low. The production of $\mathrm{CO} 2$ was slightly increased due to the increase of burning oil and coals for electricity. It was estimated that the emission of $\mathrm{CO} 2$ from 2.23million tones in 1999 to 2.8 million tons in 2005 [10].

In its 2003 energy policy Tanzania recognized the need for improving the use of renewal energy due its 
growing energy demand and high dependence on non commercial energy. It stated clearly that "Biomass energy for the foreseeable future will remain the main energy Source". Some of the renewable energy used in Tanzania includes improved wood stoves, charcoal production practices, solar energy and wind energy. The government of Tanzania intended to build a good environment for the use of renewable energy by establishing codes of practice, guidelines and standards for renewable energy technologies, promote efficient biomass conversion and end-use technologies for saving resources, reducing the rate of deforestation, and plan for safe renewal energy production by co-operation with other relevant stakeholders [5].

\section{Chinese Energy Policy}

China energy policy is continually changing after implementing different five year plans; China has successfully achieved a target of expanding energy production and consumption by increased energy production by more than 32 folds from the implementation of its first plan to eleventh five year plan. Each five year plan puts specific emphasis on reaching a target for example the sixth five year plan stressed on reducing energy consumption per unit, the eleventh plan stressed on providing energy efficiency and reduction of consumption of around 20 per cent of the unit GDP and reduced to further around 16 per cent as stated in twelfth five year plan [11].

Various energy conservation measures were implemented to achieve a reduction of energy consumed per unit of production from 2.6 to 3.5 per cent per year. The major energy consumers were expected to reduce consumption in production from 3 to 12 percent per year and energy consumption per RMB 1000 of national income was reduced from 1.29 Tce to 1.14 Tce. The Chinese government's ninth Five-Year Plan set energy conservation target of 5 percent annually [11].The efficiency was improved on heavy industries such as coal processing and electrical power generation, metallurgy, cement, paper, textiles, and oil $[11,14]$. Energy consumption per ton of steel reduced from 1.63 to 1.55 Tce and reduced further to 1.45 Tce during the ninth five year plan. The Chinese government declared in its eleventh and twelfth five years plans to reduce consumption per unit GDP by 20 percent and 16 percent respectively in order to increase energy efficiency [11].

The Chinese government is working hard to control emission and pollution by setting a different standard to be observed in a control measure for example it planned to reduce SO 2 by 10 percent in the end of 2010 , but that target was surpassed to a reduction of 14 percent. The Government intended to reduce the emission of $\mathrm{SO} 2$ further to 8 percent. The control of the greenhouse gas emission was addressed in Chinese eleventh five year plan with no specified target, but the twelfth year plan mentions various measures to reduce emissions such as adjusting both industrial and energy structures, increase forest sinks for reducing energy consumptions and carbon dioxide $\mathrm{CO} 2$ emission intensities [11]. The figure 3 below shows $\mathrm{CO} 2$ emission per unit of electricity generation in China, the figure 1 shows that China has successfully reduced the amount of emission by $300 \mathrm{Mt}$ in 2012, this amount is better by half than that attained in 2011 [21].

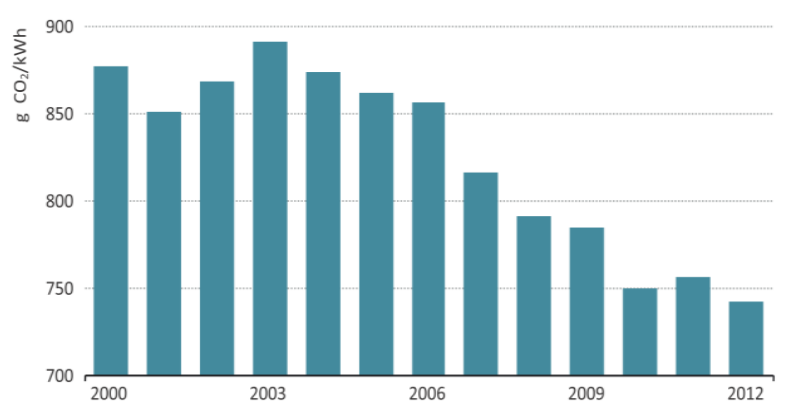

Figure 3 : $\mathrm{CO} 2$ emission per unit of electricity generation in China. Source: World Energy Outlook Special Report 2013

There is improvement in the use of renewal energy sector in China; the consumption of renewal energy increased by approximately 39.9 times from 2002 to 2012. The utilization of new and renewal energy reached to 31.9 million tonnes of oil equivalent (Mtoe) in 2012 from 0.8 Mtoe in 2002. The supply of electricity from Nuclear Power Plant has increased from 5.7 Mtoe in 2002 to 22.0 Mtoe in 2012 and strengthen energy supply to the National grid [20]. The long term and medium Plan for nuclear energy has been set, it is estimated that by 2020 nuclear energy installation would reach 40 million $\mathrm{kW}$ hours and electricity generation would reach 260 to 280 billion KW hours. The government of China has stressed on developing nuclear power efficiently on the basis of 
nuclear security to avoid situations occurred in the Fukushima Power Plant in Japan and in Russia [11]

\section{Comparison}

Despite its ambitious goal of providing its people with reliable, affordable energy supplies and their use of rational and sustainable manner, the Tanzania energy policy does not successful implement due to its ambitious objective to support national development goal, Tanzania has not achieved this, it was found that over 90 percent of its people have no access to commercial energy, most of them depends on wood-fuel, furthermore the estimates revealed that 2 per cent and 39 per cent respectively of the rural and urban residents have access to electricity [12]. It was observed that due to the higher demand of electricity and reliance of the hydro power electric consumers can have no power up to 12 hours for five days of a week [13]. Unlike Tanzania, China is doing very good in implementing its policy by using its five year plans, for example, it has successfully increased energy production by 32 folds, using those plans with different sets of objectives each five years, various targets like increase energy production, energy efficiency, reducing consumption per GDP have been achieved.

It was reported that energy efficiency can contribute to social equity by reducing energy prices and increase energy availability, but achieving energy efficiency is very expensive it needs the knowledge of consumer behavior and technologies [7]. Tanzania is struggling to provide its people with reliable and sustainable energy but this move has not yet been successful, the grid power distribution is inadequate [13], the technology used in production, distribution of electricity is very important in reaching energy efficiency. The technology used in Tanzania is very old which lead to energy loss [8], the price of energy in Tanzania is not stable it sometimes change not less than two times in a year, For example the price of petrol changed from $1300 \mathrm{TZS}$ per litre to $1420 \mathrm{TZS}$ per litre from June to December 2009, and continually changed from 1540 to 1560 TZS per litre from May to June 2010 [8]. The study on energy efficiency in shelter adequacy in Tanzania found that energy efficiency is inefficient in Tanzania [13].
Various energy policies were carried out to improve energy efficiency with the aim of alleviating energy shortage and climate change since late 1970.Despite its very low energy efficiency compared to developed countries; China struggled to improve energy efficiency and managed to reach an energy saving of 3.9 percent in a span of 25 years. It also achieved several targets of reducing energy consumption, met its energy needs and improved the efficient use of energy approximately three times [14].

Despite Tanzania is a non industrialized country as China and relying much on subsistence agriculture, there is an increase in emissions of $\mathrm{CO} 2$ due to the increase in economic activities like transportations, industries, on the other hand high rate deforestation reduce the absorption of $\mathrm{CO} 2$, It was estimated that there was an increase in $\mathrm{CO} 2$ from $0.0 \mathrm{kt}$ to $1052.43 \mathrm{kt}$ from 1970 to 2008 [15] , the emission in 2008 was estimated at 6.49 Mtoe and later increased to 6.63 Mtoe in 2009 with emission per capita of 0.16 [16]. China contributed 19 percent of world $\mathrm{CO} 2$ emissions from 5101 million tons of energy consumption. The estimates showed that China would consume 3819 Mtoe due to its increasing energy demand in the year 2030 and would become a world leader in CO2 emission after 2010 [17]. The CO2 emission increased from 6803.92 mil tonnes in 2008 to 7710.50 mil tonnes in 2009, China became a world number one emitter of $\mathrm{CO} 2$ with lower per capita tonnes of 5.83 [16]. In 2012 has reduced the emission of $\mathrm{CO}_{2}$ by half comparaed to the amount of emission in 2011[21].

The Tanzania's National energy Policy 2003 emphasized the development of renewable Energy resources and technologies. Tough Tanzania has started production and exploration of natural gases but is still faced with policy challenges [12], among the problems include the lack guiding policy and legal framework, inadequate research and development of biofuels and the problem in conservation and environmental issues [12].

The importance of using renewable energy was addressed in the Chinese eighth year Five year plan, the tenth Five year plan identified different target for the development of renewable energy, these targets include formulating renewable energy development plan, setting targets of developing industry and the 
mechanism of introducing renewable energy. The promotion of renewable energy was welcomed by establishing various policy initiatives in both provincial and National levels, Research and development for renewable energy are funded using subsidies [18]. A loan of 1 billion RMB was used for small and medium sized enterprise to fund renewable energy projects; a Renewal energy law was established in 2005 to facilitate the renewal energy sector in China [19].

\section{Conclusion}

This paper has shown that the energy policy objectives can differ from one country to another and the implementation of the policy is very important in realizing the goal addressed in a particular policy. Tanzania has not been successful in the implementation of its policy; with only 90 percent of its people depend on fire woods and other forms of biomass. There exists a very big gap between Tanzania and China due to the differences in technological developments reached by those two countries. There is no energy efficiency in Tanzania with almost 10 percent of its people has access to commercial energy which is subject to fluctuation of price. Tanzania is a non Industrial country has very low emissions compared to China with higher emission in the world, but its emission is gradually increasing.

\section{References}

[1] WEC, Policies for the future: 2011 Assessment of country energy and climate policies, World Energy Council, 2011.

[2] WEC, Pursuing sustainability,2010 Assessment of a country energy and climate policy, World Energy Council, 2010.

[3] http://www.eia.gov/totalenergy/data/annual/pdf/sec 2.pdf

[4] U.S.Congress, Energy in Developing Countries,OTA-E-486, Washington, DC: U.S. Government Printing Office , 1991.

[5] URT, The Energy Policy of Tanzania. Government printer, Dar es Salaam Tanzania, 2003
[6] E.Sawe, Sustainable Charcoal Production for Poverty Sustainable Charcoal Production for Poverty Reduction in Tanzania,TATEDO Tanzania, 2009.

[7] D.Oleg, and C. Ralph, Trends in Consumption andnProduction, Household Energy Consumption, United Nations, 1999

[8] Ewura, Annual report for the year ended 2009, Ewura Tanzania, 2010.

[9] S. Mbuligwe and G.Kassenga, "Automobile air pollution in Dar es Salaam City Tanzania," The Science of the Total Environment 199 pp. 227-235.1997.

[10] Helio International, Energy and Sustainable Development in Tanzania Sustainable Energy Watch, 2005/2006.

[11] X.Yuan and J.Zuo, "Transition to low carbon energy policies in China-from the Five-Year Plan perspective,” Energy Policy 39 pp 3855-3859, 2011.

[12] H.Sosovele, "Policy Challenges Related to Biofuel Development in Tanzania," Africa Spectrum, 45,1,117-129,2010.

[13] L.Mosha, "Realities of Energy Efficiency in Shelter Adequacy in Tanzania," PREA Workshop, 2006.

[14] X. Zhang, X.Cheng, , J. Yuan, and X.Gao, "Total-factor energy efficiency in developing countries," Energy Policy, 39 pp. 644-650. 2011

[15] Information on http://www.indexmundi.com

[16] http://www.guardian.co.uk.

[17] S.Dhakal, "Urban energy use and carbon emissions from cities in China and policy implications," Energy Policy 37 pp. 4208-4219, 2009.

[18] J. Cherni, and J.Kentish, "Renewable energy policy and electricity market reforms in China," Energy Policy 35 pp. 3616-3629, 2007.

[19] W. Feng, H. Yin and , S. Li "China's renewable energy policy: Commitments and challenges,' Energy policy 38 pp. 1872-1878,2010.

[20] BP. BP Statistical Review of World Energy . 2013

[21] I.E.A.Redrawing the energy-climate map World Energy Outlook Special Report. 2013 